\title{
An empirical study for evaluating performance of King Abdulaziz International Airport with six sigma
}

\author{
Abdullah Basahel, Abdullah M. Alqarni \\ Deparment Faculty of Economics and Administration, King Abdulaziz University \\ Jeddah, Saudi Arabia \\ *Corresponding author, e-mail: abasahl@kau.edu.sa, a.mq1@hotmail.com
}

\begin{abstract}
This research is intended to evaluate the efficiency of proceures and processes used by the King Abdulaziz International Airport (KAIA) in Jeddah, Saudi Arabia with the help of Six Sigma. For, we have framed different objectives for analyzing the effect of six sigma in decision makings and quality control of the KAIA. The aim is also to find out the relationship of Six Sigma on an information system used by KAIA. We have used the qualitative research method (semi-structured interview method) with the target population of five employees working at KAIA. Qualitative data was collected from participants through transcribed, audio-recorded and codes. Thematic analysis was carried out in order to obtain the study result. Our study finds that there is a significant effect of Six Sigma in streamlining of all the processes of KAIA, which contributed towards the improvement of the quality and providing better control. We found that the KAIA applies KPIs to measure the decision makin, empowering the decision makers or managers. We have also reflected on the role of Six Sigma towards the effective performance of individuals in finance, customer support, and internal business process and team development.
\end{abstract}

Keywords: airport, KPI, performance, quality,control, six sigma

Copyright $@ 2019$ APTIKOM - All rights reserved.

\section{Introduction}

Six Sigma is a set of techniques and tools which can be used assess the effectiveness of business processes. Its main usage though is to provide a problem solving methodology, which is capable to define, measure, analyze, improve and control the process improvement. Montgomery \& Woodall (2008) express that six sigma is a factual method that allows a logical assessment of procedures and exchanges for the decrease of changeability and the expulsion of imperfections

Background Six Sigma is an arrangement of strategies and devices for process change. It was created by Motorola in 1986. Jack Welch made it integral to his business procedure at General Electric in 1995. Today, it is utilized as a part of numerous mechanical segments. Six Sigma tries to enhance the nature of process yields by recognizing and evaluating the reasons for defects (mistakes) and limiting fluctuation in assembling and business forms. Six Sigma was utilized by many organizations as a well-organized procedure in order to enhance the overall performance of all processes carried out by organisation's in general through developing Key Performance Indicators (KPI) [1].

Further, it is used chiefly to exclude the defects with the intention of achieving constant improvement in the quality of all products. i.e. it acts as a good quality controller and acts as the best decision maker. After seeing the extraordinary improvements resulted from the implementation of Six Sigma in numerous sectors like health and banking care, its usage was spread over different organizational areas, especially information system.Some reports have revealed that, the organisations which applied Six Sigma, achieved the increasing performance of the company with respect to enhanced quality and productivity [2, 3]. A few associations (Motorola, GE, Kodak, Maytag, Sony, Johnson and Johnson) have incorporated lean and six sigma as a method for adjusting for the confinements in every strategy and this procedure is hints to as lean six sigma [4].

It is observed that organization's can apply Six Sigma for overall process improvement through association with the information system. For instance, the study of [5] specified that the role of Six Sigma on the information system and shows that the positive effect on the growth of the organization. Considering the growing importance of Six Sigma on organizational behavior at each and every stage induce the us to carry out this research. In terms of world prosperity and global economic development, the airport sector is an important part of global business. Because of the fact, the airport is a capital-intensive industry, quality 
control in operations, maintenance, and the building has constantly captivated the stakeholders' attention. Therefore, numerous airports have agreed to implement QMS (quality management systems) to embrace and advance safety in the operations, comprising: International Safety Management (ISM) code ISO quality management systems, and TQM (Total Quality Management).

The reason for choosing this sector is due to personal experience of the researcher towards them and also growing importance of Six Sigma in this sector specifically for decision making and control management, used as the key performance indicator for decision making and the increasing use of information system along with Six Sigma motivates the researcher to take this concept.

Problem statement, research aim and objectives. In this article we shall use six sigma to evaluate the efficiencies of proceures and processes used by the King Abdulaziz International Airport (KAIA), located in Jeddah, Saudi Arabia. is considered as the most significant one which serves as a gateway for Umrah and Hajj pilgrims performed at the Holy Mosque in Makkah [6 -10]. In addition, it is the home for the world's fourth biggest terminal: the Hajj terminal which is 510,000 square meters in size. It has four terminals namely South Terminal (exclusive to Saudi Arabian airlines), North Terminal (for forign airlies), the Hajj terminal (exlusive for Hajj and Omra pilrims) and the Royal Terminal (only used by the King of Saudi Arabia and his guests

In this article we shall use six sigma to evaluate the efficiencies of proceures and processes used by the KAIA. This research is intended uses a mixture of descriptive and exploratory study for inductively examining and assessing the effect of quality methodologies (Six Sigma) on the behaviour of the King Abdulaziz International Airport (KAIA). For, the following objectives are framed.

- To analyse the effect of six sigma in decision making and quality control of KAIA

- To explore the role of six sigma in decision-making procedures of KAIA by applying Key Performance Indicators (KPI).

- To find out the relationship of Six Sigma on an information system in KAIA

- To provide suggestions to the management team of KAIA, in order to further enhance the activity of Six Sigma on decision making and organizational behaviour.

The following are the research questions. Main Question: What is the role of quality methodologies like Six Sigma on organizational behaviors (decision making, quality control, use of information system and KPI for decision making procedures)? Secondary Questions:

- How to explore the role of Six Sigma in decision-making procedures of the KAIA by applying Key Performance Indicators (KPI)?

- What is the main role-playing and impact of Six Sigma on decision making and quality control among employees at the time of quality issues?

- What is the relationship of Six Sigma on an information system in KAIA?

Significance, scope and limitations of the study. Given the lack of studies of assessment of role and impact of Six Sigma on decision making and quality control management in the airport, is necessary. This will be proved in this research is added advantage and it will become more significant research for future researchers in line with this concept. Moreover, the increase of information system in society and its application along with Six Sigma will give a major idea to the organization in which have more interest in applying quality methodologies for process and quality improvement.

The research scope is established to assist the central of this dissertation that is to improve the response and to influence Six Sigma on quality control management and decision making in the airport sector. Therefore, the document only describes the related methods and theories to a level upon which they have utilized to outfit the aims that are clarified above in preference to providing a detailed mathematical and theoretical discourse of the theories. Additionally, it is the purpose of this research to inspire and stimulate more and more academic studies in Six Sigma and support its applications in different areas. But, in situations of lack of objective information, the data for the explained cases are illustrated in this study is from the domain experts in the choosing airport.

\section{Literature Review}

\subsection{Six Sigma}

In [11] it is stated that Six Sigma has been introduced for quality improvement which was developed around 25 years. It was initially used by Motorola Corporation in the year 1986. Numerous large multinational companies all over the world have deployed Six Sigma and were benefited with substantial popularity over years. [12] observed that the Six Sigma program was globally approved as available effective process development systems for businesses. It was widely used in business areas which includes

APTIKOM J. CSIT Vol. 4, No. 2, 2019: 81 - 90 
servicing and manufacturing settings, and recently enlarged for financial institutions, healthcare organization, hospitality, and education.

As a methodology: Six-Sigma is a systematic, highly disciplined, customer-centric and profitdriven business improvement initiative that is based on a rigorous process focused and project-driven methodology. Six Sigma uses data and statistical analysis to measure and improve the company's operational performance via the DMAIC framework [13].

As a management system: It is often discovered that one of the difficulties facing Six Sigma projects is sustainability. Simply applying the methodology is not sufficient to drive the desired breakthrough improvements and results that are sustainable over time. It is found that sustainable and breakthrough improvements are realized by those organizations whose leadership has embraced Six Sigma and incorporated it into their vision, strategies and business objectives. When practiced as a management system, Six Sigma is a high performance system for executing business strategy.

\subsection{Importance of Quality Management}

Market economy necessarily brings with competition among the enterprises and the result of competition is the survival of the fittest. Under the condition of serious competition, it is impossible for a company to realize and improve profits only relying on reducing cost or entrepreneurs' inspiration and force. The final effect is an enterprise' strength consisting of many contents, among which quality is the most direct and important factor. The companies surviving a long time in the market are those which recognize the importance of market competition and understand the profound meaning of 'quality is the life of a company' [14]. Today market competition has changed from the price competition to quality competition. Quality is the passport for a company to enter into the market and participate in the competition [15]. Without the quality advantage, companies consequentially will be in the inferiority

Under the condition of the market economy, enterprises are engaged in various economic activities, all of which are purposeful for pursuing profit [16]. In order to realize and improve profits, no matter with what method, enterprises must base on the quality advantage of their products and service to attract more customers. This can be explained by Marx's theory of use value and value. The Prerequisite of the products accepted by the customers is that it must be useful for the customers [17], that is to say, customers buy products' use value and the companies gain the products' value. The quality level of the products directly decides its use value. Generally products with high quality can sell high price, which will bring high profit to companies. In other words, high quality means high profit. Therefore guaranteeing and improving products' quality is the foundation for companies' survival and development.

\subsection{Role of Six Sigma in of Quality Management}

Six Sigma has enjoyed an unprecedentedly long period of popularity. It attracts organizations by achieving great benefits including tangible results, such as cost saving and waste reduction. [18] stated that Six Sigma can generate sustained success, set a performance goal for everyone, enhance value to customers, accelerate the rate of improvement, promote learning and "crosspollination" and execute strategic change. Six Sigma is important because it scores much higher over other quality improvement techniques such as TQM. Business organizations employing TQM just focus on achieving predetermined quality levels, which certainly improves efficiencies but does not allow the organization to realize the full potential. Six Sigma is different as the focus here is to make consistent quality improvements until business processes are fully optimized. As soon a certain quality level is achieved, the organization shifts gears and starts concentrating on achieving other levels of quality. The whole process continues until all the business processes are fully optimized.

Six Sigma concepts and methodologies stress the use of statistical tools and techniques for improving quality and reducing defects. The dependence on hard facts and figures automatically ensures that whatever decisions are taken will have the desired effect on the quality of goods or services and the efficiency of business processes. An experienced production manager may be the right person to make quality-improvement decisions but if the decisions are based solely on gut feelings and preconceived notions, the decisions may not have the desired effect, especially if the task is to make adjustments in a complex business process. The inherent ability of Six Sigma to produce the desired results has thus increased its importance in today's business world.

Another reason for the ever-increasing popularity and importance of Six Sigma is that it really helps when it comes to handling competition, which has increased considerably in today's business world. Business organizations worldwide have realized that in order to beat the competition, they will have to offer better quality products or services to their customers and that too at competitive rates. The importance of Six Sigma has increased manifold in the last two decades and is set to increase even more in the coming 
years as more and more businesses realize its benefits. Six Sigma is anticipated to maintain its dominance over all other existing quality improvement techniques because it is flexible and can be altered to suit the requirements of new businesses that might come up in the near future. We can never be too sure about the future but as far as the present is concerned, Six Sigma is certainly calling the shots across all types of industries worldwide [19]. In the airport, the Six Sigma was used in Check-in service is that passengers need experience flow, and decides the first impression given passengers, so it plays an important role on the ground service quality [20].

Six Sigma is a project-based structured methodology aiming at reducing process defects and variability by taking account of customer requirements. Its implementation uses a five-step DMAIC methodology Figure 1 DMAIC provides a roadmap with tools for conducting projects. Although similar to the PDCA cycle, the DMAIC emphasises results measurement and control, and has extensive use of statistics. DMAIC model has been adopted by many companies in Six Sigma implementation, such as ABB, Caterpillar and Intersil. It provides a consistent approach for organizations in adopting Six Sigma. DMAIC focuses on customer needs and continuous measurement to achieve improvement on current processes which are essential aspects of shipping company quality improvement. In the meantime, it also offers the opportunity to redesign the processes if it becomes necessary. Six Sigma did not introduce new tools; instead, it provides a different methodology for implementation which focuses on business infrastructure and bottom-line results.

As shown in Figure 1, when implementing Lean Six Sigma for a process, business or product implementation, you must address each stage in the DMAIC Cycle. As per [21], there are five stages of the DMAIC process namely, Define, Measure, Analyse, Improve, and Control. Figure 2 shows Etymology of six sigma process. All the statistical assumptions of the Six Sigma model are highlighted in normal distribution graph. Sigma $(\sigma)$ measures the distance on the horizontal axis between the curve's inflection point and mean $(\mu)$. If this distance is greater than the spread values are found. The green curve shows its value larger than $\sigma=1$ and $\mu=0$. The lower and upper specification limits (LSL and USL individually) are staying at a distance of $6 \sigma$ from its mean position. With the normal distribution properties, values lay at longer distances are not the same? Even though if the mean is moved by either left or right for $1.5 \sigma$ for the future (1.5 sigma shift is colored with blue and red) will still have a safety cushion. This is the reason why Six Sigma would aim for processing the mean, in the worst case it is $6 \sigma$ away from the shortest specification limit.

\subsection{Involvement of Six Sigma on Airport}

Lean Six Sigma tactics are techniques that rely on collaborative team efforts to improve processes. Lean-six-sigma is considered a process that can improve services or products continuously in order to achieve high product/service quality, competitive costs and reduced delivery times, leading to the satisfaction of customers [22].

The aviation industry nowadays requires continuous improvement to raise the levels of customers' satisfaction. This satisfaction can be achieved through many managerial procedures (such as lean-six-sigma procedures), in order to ensure the business's viability. Airports are complex organizations whose areas of comparative advantages and efficiency hinge on elements that the airport management is more likely to control and on applying the lean six-sigma philosophy in such areas.

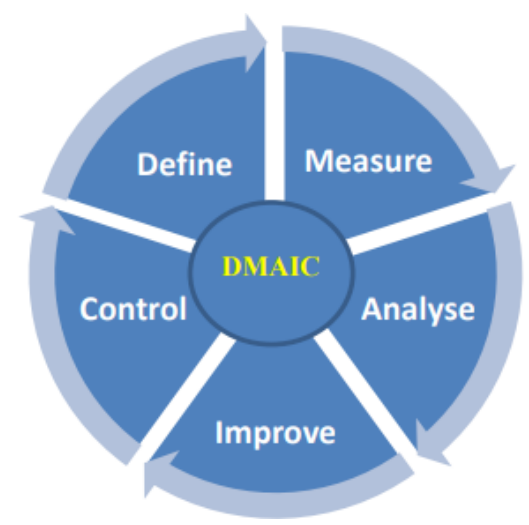

Figure 1. Six sigma DMAIC model (Source: Qu, 2014)

APTIKOM J. CSIT Vol. 4, No. 2, 2019: 81 - 90 


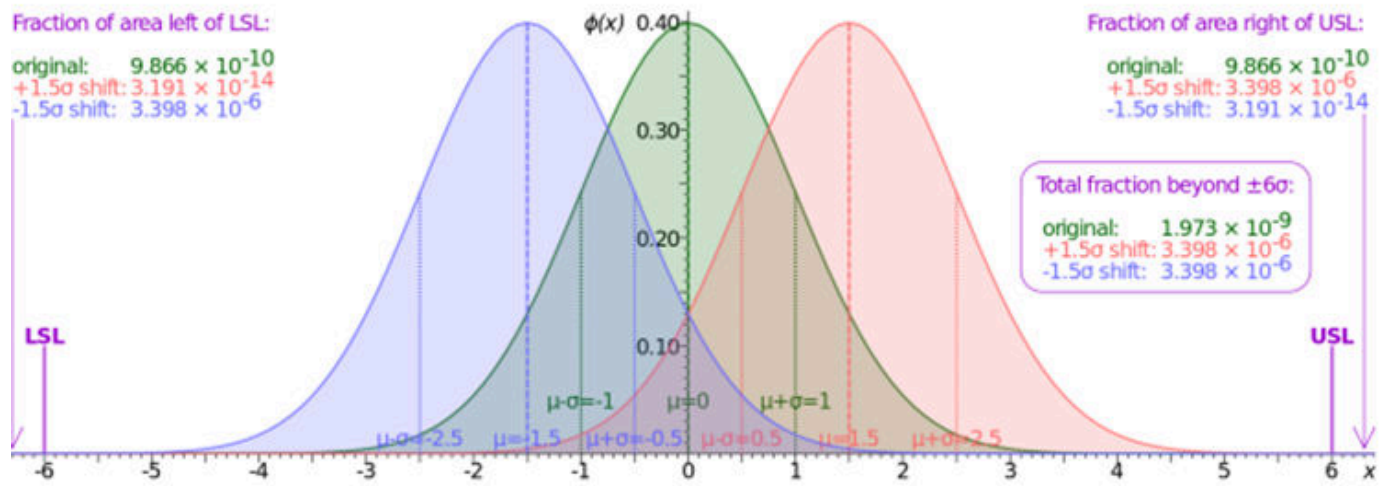

Figure 2. Etymology of six sigma process (Source: Swink and Jacobs, 2012)

This will ideally result in the optimization of resources, efficiency in performance and the continuous gradual reduction of all forms of waste [23]. On the one hand, Safety is the top priority, but, through lean tactics, TSA can speed things up while keeping everyone safe. In $2016,98 \%$ of fliers waited 30 minutes or less for screening between Memorial Day and Labor Day, and, about $92 \%$ waited less than 15 minutes, according to the Department of Homeland Security (DHS) [24]. There is numerous researcher also examined the application of Six Sigma methodology to enhance the airport efficiency and productivity [25]. According to the report of [24] lean Six Sigma methodology was applied to reduce the waiting time. Reports revealed thatKAIA conducted training program. [26, 27]. Further the organization conducted a masterclass for key performance indicators include in-depth synthesis of key performance management trends and practices. It focuses on the essential tools and techniques that must be implemented for successful performance management architecture [28]. Additionally, a report like [29] pointed out the role of Six Sigma on KAIA.

\section{Research Methodology}

As per the framed research objectives, the descriptive and exploratory design is suitable since the researcher aimed to describe the Six Sigma event in decision making, information system and quality control of products of KAIA. There are there are two methods of data collectionnamely, primary and secondary data [30]. Interview method is be used as a piece of in the primary data collection method. This method consists of three types of data, which include semi-structured, unstructured and structured. Structured type has predefined questions, semi-structured are more flexible and unstructured does not have the predefined structure [31-34]. Our study is based on a semi-structured interview technique carried out via face-to-face. This technique permited us to explore the unique experience of employees working at the KAIA. Table 1 shows the framed questions, which are related to the research objectives.

\subsection{The Questionaire}

The research results are presented in this section based on the interview with senior managers. In this chapter, findings are summarized, and chief findings are tabulated and presented in a tabular form which was found to be addressing the framed research questions in chapter 1 . Further this form of tabulation generates more understanding of readers. Respondent's details were mentioned as Res_01, Res_02, Res_03, Res_04 and Res_05 for quick understanding. 
Table 1. Questionnaire and its relation to research objectives and questions

\begin{tabular}{|c|c|c|}
\hline \multirow{2}{*}{ Questionnaire } & \multicolumn{2}{|r|}{ Relation } \\
\hline & Research questions & Research objectives \\
\hline $\begin{array}{l}\text { How do Six sigma influence quality } \\
\text { control of KAIA? } \\
\text { How do Six sigma influence decision } \\
\text { making of KAIA? } \\
\text { What is the role of Six Sigma on decision } \\
\text { making procedures of KAIA? } \\
\text { What is the relationship of Six Sigma on } \\
\text { the information system in KAIA? } \\
\text { Provide your suggestions to the } \\
\text { management team of KAIA to further } \\
\text { enhance the activity of Six Sigma on } \\
\text { decision making } \\
\text { Provide your suggestions to the } \\
\text { management team of KAIA to further } \\
\text { enhance the activity of Six Sigma on } \\
\text { another important organizational } \\
\text { behaviour }\end{array}$ & $\begin{array}{l}\text { What is the role of quality } \\
\text { methodologies like Six Sigma on } \\
\text { organizational behaviors } \\
\text { (decision making, quality } \\
\text { control, use of information } \\
\text { system and KPT for decision } \\
\text { making procedures)? }\end{array}$ & $\begin{array}{l}\text { To analyse the effect of six sigma in decision } \\
\text { making and quality control of KAIA } \\
\text { To explore the role of six sigma in decision-making } \\
\text { procedures ofKAIA in Jeddah by applying Key } \\
\text { Performance Indicators (KPI). } \\
\text { To find out the relationship of Six Sigma on an } \\
\text { information system in KAIA } \\
\text { To provide suggestions to the management team of } \\
\text { KAIA in order to further enhance the activity of Six } \\
\text { Sigma on decision making and organizational } \\
\text { behaviour. }\end{array}$ \\
\hline
\end{tabular}

\title{
4. Analysis and Results
}

As explained earlier, we shall use qualitative analysis to conclude the results on our case study. The research results are presented in this section based on the interview with senior managers. Figure 3. shows the effect of Six Sigma on decision making process of organizations. In this aspect, it is noticed from the finding as for the role of Six Sigma involved in decision making of process streamlining

\subsection{Effect of Six Sigma on Decision Making of KAIA by KPIs}

Figure 1 shows the effect of Six Sigma on decision making process of organizations. In this aspect, it is noticed from the finding as for the role of Six Sigma involved in decision making of process. Evidence of this came from a respondent who stated that "Six Sigma is positively influencing the decision making of KAIA. It mainly helps to streamline the process and get things done efficiently (Res_01)". Another respondent said "Everything has positives and negative but the positives with Six Sigma is more when compared to the negatives. It helps towards better organizational goals (Res_04)". Third respondent was unsure of the effectiveness of Six Sigma on decision making (Res_05). This is may be the respondent is not aware of the effects of Six Sigma on decision making for his or her organization.

\section{Effect of Six Sigma on decision making}

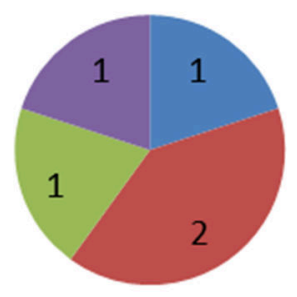

\author{
Streamline the \\ process \\ Saving time, cost \\ and resources \\ Better \\ organizational goals
}

Figure 3. Effect of Six Sigma on decision making (Source: Responses) 


\title{
Effect of Six Sigma and quality control
}

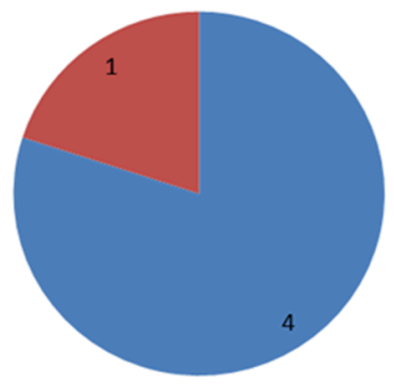

\author{
Increasing the quality
}

n streamlined the process to work efficiently and effectively

Figure 4. Effect of Six Sigma and quality control (Source: Responses)

Yet another respondent attributed to Six Sigma being helpful in saving time, cost and resources (Res_02). The fifth respondent said that Six Sigma has been very help to the organization, specially with time and cost (Res_03. The resultant of these responses has been shown in Figure 3 and Figure 4.

\subsection{Effect of Six Sigma and Quality Control}

In order to obtain the above objective, the study findings involve examining the Six Sigma effect in decision making and quality control of all the services carried out byKAIA. Study results reveal that there is a significant effect of Six Sigma in streamlining of all the processes of the organization as a result, the quality was also improved and controlled. In order to understand the effect of Six Sigma on quality control, the questions related to this concept were asked among respondents. Majority of the respondents revealed that the Six Sigma involves in enhancing the quality which was observed obtaining positive customer feedback in testimonials and live experience of respondents in decreased cycle time, waste and rework errors. However, one of the respondents revealed that the Six Sigma increased the quality through streamlining the process as a result, all the process in the organization going well in a more effective and efficient manner. Definitely quality is has improved the quality. It streamlined the process to work efficiently and effectively. (Res_03)".

From the finding of the above figure, it is clear that there is a positive effect of Six Sigma on quality control. Though, only one respondent shows that the effect of Six Sigma involves in streamlining the process.

\subsection{Role of Six Sigma in Decision Making by KPIs}

It is explored from the study findings as the role of Six Sigma in decision-making procedures of KAIA by applying KPI. Chosen organization apply KPI to measure the decision making the power of decision makers or managers. In this aspect, the role of Six Sigma was reflected in the effective performance of individuals in finance, customer support, and internal business process and team development.

To obtain the role of Six Sigma on decision making procedures by applying Key Performance Indicators (KPI) and the study findings of majority show that strong decision making skills among individuals in team development $(\mathrm{n}=2)$. The first respondent stated that Six Sigma support decision making of the financial performance of the organization. The role of Six Sigma increasing the performance of employees in terms of customers support. Similarly, another respondent shared their opinion as the role of Six Sigma showed performance in financial and some internal business processes

Figure 5 represents that the Six Sigma involves in decision making with the help of key performance indicators like finance, customer support and internal business process and team development. 


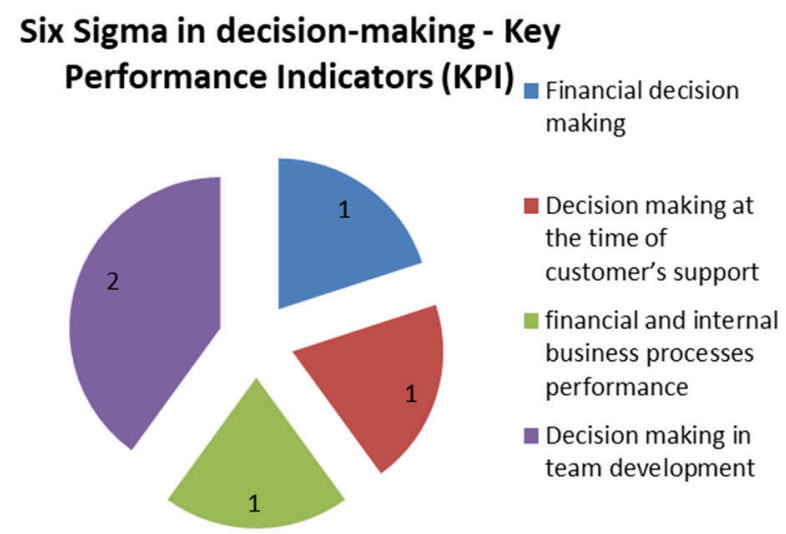

Figure 5. Six Sigma \& decision-making procedures by KPIs (Source: Responses)

\subsection{Relationship of Six Sigma on an Information System}

The study findings showed the relationship between Six Sigma and information system as a result information system quality of organization was increased. From the study findings, it is clear that the information system used in the airport would increase the time and cost saving as a result the organization growth also increasing along with good quality control. In line with this, there are numerous researchers have made the research on examining the impact of Six Sigma on information system used in the organization.

With respect to the role of Six Sigma on the information system, the respondents shared as the application of Six Sigma on information system revealed that it is cost effective and time saving $(n=2)$.

Further the respondents state that the role of Six Sigma on information system can increase customer satisfaction $(\mathrm{n}=2)$. One of the respondents revealed that the time management is effective on using information system in the organisation especially it shows the effect of Six Sigma. The results are shown in Figure 6, which confirmed that the effect of Six Sigma for an organization by using information system. It is understood that its effect enhances customer satisfaction, cost saving and time efficient.

\section{Relationship of Six Sigma on an information system}

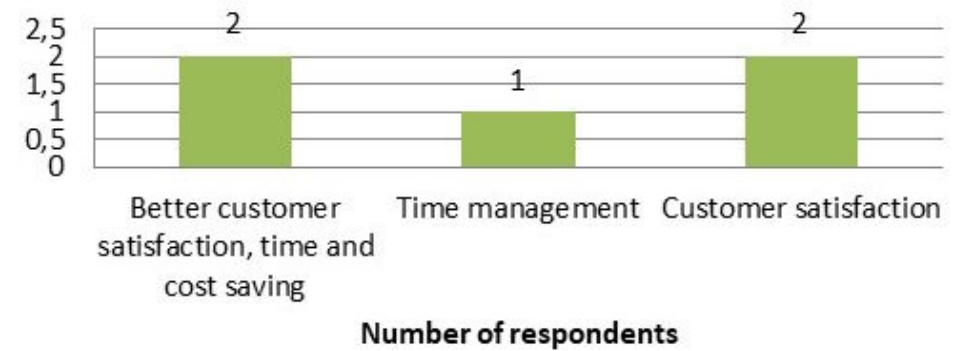

Figure 6. Six Sigma \& IS (Source: Responses)

\section{Conclusions}

As a descriptive and exploratory study, this research mainly targets on finding the impact of quality approaches such as Six Sigma on the organization's behavior such as KAIA. The research focuses to respond to the given queries:

- How to explore the role of Six Sigma in decision-making procedures of KAIA by applying Key Performance Indicators (KPI)?

- What is the main role-playing and impact of Six Sigma on decision making and quality control among employees at the time of quality issues? 
- What is the relationship of Six Sigma on an information system in KAIA?

The solutions for the given queries were identified with the help of the interview process studied from the past identical studies, and also with the thematic examining methods utilized to investigate the qualitative content. Since the literature review process was carried out seriously all over the practical and empirical research parts, it permitted validations, comparisons, and reflections of the identified solutions against the other known discoveries of the scholar. Further the research's exploratory feature has established a considerable place for the researcher to obtain good understanding about the circumstances of the company that finally assisted to state an appropriate framework of measurement for assessing the decisionmaking procedures, information system and quality control among employees at the time of quality issues. The findings can be summarized as follows:

- It is noticed from the finding as for the role of Six Sigma involved in decision making of process streamlining of the organization

- Majority of the respondents in the study revealed that the Six Sigma involves in enhancing the quality which was observed obtaining positive customer feedback in testimonials and live experience of respondents in decreased cycle time, waste and rework errors

- The study findings of majority show that strong decision making skills among individuals in team development

- Application of Six Sigma on information system revealed that it is cost effective and time saving

- Overall the study respondents give suggestions to enhance the activity of Six Sigma on decision making and also organizational behaviour

\section{References}

[1] Panagopoulos, I, Atkin, C. and Sikora, I. Developing a performance indicators lean-sigma framework for measuring aviation system's safety performance. Transportation Research Procedia. 2017; 22: 35-44.

[2] Delgado, C, Ferreira, M. and Castelo Branco, M. The implementation of lean Six Sigma in financial services organizations. in M. Leseure. Editor. Journal of Manufacturing Technology Management. 2010; 21(4): 512-523.

[3] George, M. Lean Six Sigma: Combining Six Sigma Quality with Lean Production Speed. Upper Saddle River, New Jersey, United States: McGraw-Hill Education. 2002.

[4] Arnheiter, E. D. and Maleyeff, J. The integration of lean management and Six Sigma. The TQM Magazine. 2005; 17(1): pp. 5-18.

[5] Chookittikul, J, Busarathit, S. and Chookittikul, W. A Six Sigma Support Information System: Process Improvement at a Thai University. Fifth International Conference on Information Technology: New Generations (itng 2008). Las Vegas. 2008: 518-523.

[6] Yamin, M, Basahel A M, and Abi Sen, A. A. Managing Crowds with Wireless and Mobile Technologies. Hindawi. Wireless Communications and Mobile Computing. 2018; 15.

[7] Yamin, M. Managing Crowds with Technology: Cases of Hajj and Kumbh Mela. International Journal of Information Technology. 2018.

[8] Mohammad Yamin and Rawan Matar. E-government Saudi Arabia - An Empirical Study. BIJIT - BVICAM's International Journal of Information Technology. 2016; 8(1): 944-949.

[9] Mohammad Yamin, Management of Crowded Events: Kumbh Mela and Hajj. Proceedings of the Golden Jubilee Conference of the Computer Society of India, Spring Publication. 2015.

[10] Yamin, M. a Socio-Cultural Overview of e-learning in Saudi Arabia. International Woman Online Journal of Distance Education, International Women Online Journal of Distance Education. 2015: 4(3).

[11] Tennant, G. (2001) Six Sigma: SPC and TQM in Manufacturing and Services. Farnham, United Kingdom: Gower Publishing, Ltd.

[12] Snee, R. D. and Hoerl, R. W. (2003) Leading Six Sigma: A Step-by-step Guide Based on Experience with GE and Other Six Sigma Companies. New York City, New York, United States: FT Press.

[13] Tang, L. C. et al. Fortification of Six Sigma: expanding the DMAIC toolset. Quality and Reliability Engineering International. 2007; 23(1): 3-18.

[14] Shubin, J. and Yuntao, C. Quality Management. Wuhan, China: Wuhan University Press. 2004.

[15] Juran, J. M. and Gryna, F. M. (1988) Juran's Quality Control Handbook. 4th edn. Upper Saddle River, New Jersey, United States: McGraw-Hill.

[16] Kun, M., Min, L. X. and Yi, L. L. (2015) Principles of Economics. 7th edn. Beijing, China: eking University Press.

[17] Deepankar Basu. The Structure and Content of Das Kapital Economic and political weekly. 2017: 52(37); 51-69.

[18] Pande, P. S., Neuman, R. P. and Cavanagh, R. R. (2000) The Six Sigma Way: How GE, Motorola, and Other Top Companies are Honing Their Performance. New York City, New York, United States: McGraw Hill Professional.

[19] Aveta (2016) Importance Of Six Sigma In The Business World, SixSigmaOnline.

[20] Xinhui, R. The application of Six Sigma methodology for check-in service in airport. in ICSSSM11. IEEE. 2011: $1-5$.

[21] Selvi, K. and Majumdar, R. Six Sigma- Overview of DMAIC and DMADV. International Journal of Innovative Science and Modern Engineering. 2014; 2(5): 16-19. 
[22] Hines, P., Francis, M. and Found, P. Towards lean product lifecycle management. Journal of Manufacturing Technology Management. 2006; 17(7): 866-887.

[23] Appelbaum, S. H. and Fewster, B. M. Global aviation human resource management: contemporary compensation and benefits practices. Management Research News. 2003; 26(7): 59-71.

[24] Newcastle Systems (2017) Lean Six Sigma Tactics Lead To Increased Airport Efficiency And Reduced Flyer Wait Times, Newcastle Systems.

[25] Riano, S. Design for Six Sigma (DFSS) Design for Six Sigma (DFSS) Improving Airport Project Delivery Improving Airport Project Delivery Gatwick Airport Gatwick Airport - A Case Study. 2010.

[26] GreyCampus (2018a) Lean Six Sigma Black Belt Training \& Certification in Jeddah, Eventbrite.

[27] GreyCampus (2018b) Six Sigma Green \& Black Belt Training \& Certification Combo in Jeddah, Eventbrite.

[28] KPI Institute KPI (Key Performance Indicators) Masterclass, Eventbrite. 2017.

[29] Sabri, S. The House of Saud in Commerce: A Study of Royal Entrepreneurship in Saudi Arabia. Sharaf Sabri. 2001.

[30] Creswell, J. W. Qualitative inquiry and research design: Choosing among five traditions. Thousand Oaks, CA: Sage. 1998.

[31] Yin, R. K. Case Study Research: Design and Methods. 4th edn. Thousand Oaks: Sage Publications. 2009.

[32] Myers, M. D. and Newman, M. The qualitative interview in IS research: Examining the craft', Information \& Organization. 2007; 17(1): 2-26.

[33] Creswell, J. W. Research Design: Qualitative, Quantitative and Mixed Methods Approaches. Los Angeles, CA: SAGE Publications Inc. 2014

[34] Denzin, N. and Lincoln, Y. Handbook of qualitative research. 2nd edn. Thousand Oaks, CA: Sage. 2011. 